\title{
Small-scale characteristics of extremely high latitude aurora
}

\author{
J. A. Cumnock ${ }^{1,2}$, L. G. Blomberg ${ }^{2}$, A. Kullen ${ }^{2}$, T. Karlsson ${ }^{2}$, and K. Å. T. Sundberg ${ }^{2}$ \\ ${ }^{1}$ Center for Space Sciences, University of Texas at Dallas, Richardson, TX, USA \\ ${ }^{2}$ Space and Plasma Physics, School of Electrical Engineering, Royal Institute of Technology, Stockholm, Sweden
}

Received: 6 November 2008 - Revised: 9 August 2009 - Accepted: 19 August 2009 - Published: 1 September 2009

\begin{abstract}
We examine 14 cases of an interesting type of extremely high latitude aurora as identified in the precipitating particles measured by the DMSP F13 satellite. In particular we investigate structures within large-scale arcs for which the particle signatures are made up of a group of multiple distinct thin arcs. These cases are chosen without regard to IMF orientation and are part of a group of 87 events where DMSP F13 SSJ/4 measures emissions which occur near the noonmidnight meridian and are spatially separated from both the dawnside and duskside auroral ovals by wide regions with precipitating particles typical of the polar cap. For 73 of these events the high-latitude aurora consists of a continuous region of precipitating particles. We focus on the remaining 14 of these events where the particle signatures show multiple distinct thin arcs. These events occur during northward or weakly southward IMF conditions and follow a change in IMF $B_{y}$. Correlations are seen between the field-aligned currents and plasma flows associated with the arcs, implying local closure of the FACs. Strong correlations are seen only in the sunlit hemisphere. The convection associated with the multiple thin arcs is localized and has little influence on the large-scale convection. This also implies that the sunward flow along the arcs is unrelated to the overall ionospheric convection.
\end{abstract}

Keywords. Ionosphere (Auroral ionosphere; Electric fields and currents; Particle precipitation)

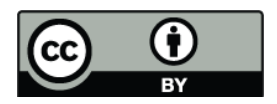

Correspondence to: J. A. Cumnock (cumnock@utdallas.edu)

\section{Introduction}

\subsection{Polar arcs during northward IMF}

Extremely high latitude aurorae appear as a variety of auroral distributions and predominantly occur during northward IMF. These aurorae may appear as single Sun-aligned arcs or as numerous arcs spread across the polar region and are typically embedded in regions of weak diffuse particle precipitation. They also vary in spatial extent and magnetospheric source regions (Bonnell et al., 1999).

A statistical study by Kullen et al. (2002), expanding on a study by Gussenhoven (1982), surveyed three months of winter hemisphere Polar UVI data and found that large-scale auroral arcs located poleward of the auroral oval may be assigned to five categories: midnight (nightside originating) arcs, bending arcs, multiple arcs, oval-aligned arcs (which include substorm recovery arcs), and moving arcs. Small-scale Sun-aligned arcs do not show up on the Polar UV images because of their low luminosity and limited spatial extent. An additional category is that called "small splits" which are arcs that appear for less than $10 \mathrm{~min}$ and/or are not separated from the auroral oval clearly enough to allow a distinction from an arc that is part of the auroral oval. They also occur at lower latitudes than the arcs investigated in this paper.

The midnight (nightside originating) arcs are those where one single arc develops at the nightside auroral oval from a triangle-like bulge and then stretches toward noon where it may reach to the dayside auroral oval (for example see Craven et al., 1986). Before fading they usually move toward the dawn or dusk side of the auroral oval. They appear during times of more active IMF conditions (i.e., high solar wind speed and high solar wind dynamic pressure with varying IMF $B_{y}$ and $B_{z}$ and at least $1 \mathrm{~h}$ of predominantly northward IMF prior to formation); see also Craven and Frank (1991). They are usually transpolar but may have a small gap near the dayside oval. Kullen et al. (2002) found that this rare type of

Published by Copernicus Publications on behalf of the European Geosciences Union. 
arc appears almost exclusively at the end of substorm recovery. These arcs may be referred to as theta aurora (single large-scale transpolar arcs aligned along the noon-midnight meridian) but are shorter lived and much less common than those theta aurorae which originate as oval aligned arcs.

Another type of arc, which is usually short-lived and faint, are bending arcs. They are hook-shaped poleward-moving arcs where one end of the arc separates from the main oval and moves toward the other side of the oval whereas the other end remains fixed (Ismail and Meng, 1982; Murphree et al., 1982; Gusev and Troshichev, 1986). Bending arcs occur during average IMF conditions with IMF $B_{z}$ fluctuating around zero and for slightly higher solar wind velocities than average. They are probably initiated by an IMF $B_{z}$ sign change. An oval-aligned arc is often seen simultaneously on the other side of the oval.

The polar cap may also fill up with multiple transpolar arcs with a multitude of different evolutions. They occur during high solar wind speed and magnitude with positive IMF $B_{z}$ on average and varying IMF $B_{y}$ and $B_{z}$. What triggers the appearance of each arc in a multiple arc event remains unclear. For an example of multiple transpolar arcs see Brittnacher et al. (1999).

Oval-aligned arcs (Murphree and Cogger, 1981) (which include substorm recovery arcs) usually appear near the dawnside or duskside oval and may become separated from the oval before they disappear. They are a common northward IMF phenomenon occurring for high IMF magnitude, often for steady IMF with similar IMF $B_{z}$ and $B_{y}$ magnitudes. They persist from tens of minutes up to hours. When oval-aligned arcs occur on both sides of the auroral region (usually during very small IMF $B_{y}$ ) the pattern is called "horse collar" aurora (Hones et al., 1989).

Single large-scale transpolar arcs aligned along the noon-midnight meridian, named theta aurora by Frank et al. (1982), form almost exclusively during northward IMF. Gussenhoven (1982) found that these transpolar arcs show increased occurrence with increasing solar wind velocity. Theta aurorae have been observed to form when oval-aligned arcs move poleward resulting in a transpolar arc aligned along the noon-midnight meridian. The oval-aligned arcs may move poleward and cross the entire polar region only when there is an IMF $B_{y}$ sign change during northward IMF (Cumnock et al., 1997, 2002). They are then referred to as moving arcs and are the longest lived (up to several hours) of the high-latitude arcs (Kullen et al., 2002). In addition, theta aurorae are observed to almost always occur when $B_{z}$ is steady northward for at least two hours prior to a $B_{y}$ sign change regardless of $B_{x}$ and dipole tilt (Cumnock, 2005) but they have also been observed when $B_{z}$ is not steady northward (for example Plate 1 of Chang et al., 1998). The Cumnock (2005) results imply that transpolar arcs occur simultaneously in both hemispheres; with a dawn-dusk asymmetry and the opposite dawn-dusk motion (Craven et al., 1991; Cumnock et al., 2006).
In a statistical study of large-scale transpolar arcs during steady northward IMF, Cumnock (2005) found that the strongest UV emissions measured in the theta aurora occur in the sunlit ionosphere. In the summer hemisphere maximum emissions in the transpolar arc (theta aurora) can range from 500 to $2000 \mathrm{R}$, in the winter hemisphere maximum emissions are less than $500 \mathrm{R}$, as measured by Polar UVI. Transpolar arcs have similar particle characteristics as the auroral oval, which suggests an origin in the plasma sheet or plasma sheet boundary layer (see also Meng, 1981; Peterson and Shelley, 1984; Frank et al., 1986; Frank and Craven, 1988; Huang et al., 1987, 1989). Obara et al. (1996) presented the probability of average energy of precipitating electrons producing small-scale Sun-aligned arcs in the night side and day side polar cap, based on a few hundred such satellite measurements. Large-scale transpolar arcs (including theta aurora) are found at the high end of this energy distribution. A detailed evaluation of observations and models has led to the suggestion that small-scale Sun-aligned arcs and theta aurora arise from importantly different physical mechanisms (Carlson and Cowley, 2005).

The range of UV emissions measured in theta aurora is lower for those arcs that form during steady northward IMF; brief decreases or southward excursions of IMF $B_{z}$ can enhance the intensity of the transpolar arc (TPA) and affect the velocity of its motion (Cumnock et al., 2000). The Cumnock (2005) study was expanded by Kullen et al. (2008) who found that the brightness of theta aurorae which occur in the summer hemisphere after an IMF $B_{y}$ sign change during steady northward IMF shows the same dependence on season and solar wind conditions as the main auroral oval except in the nightside sector. Increasing TPA brightness is associated with high solar wind speed, strongly northward IMF, high IMF magnitude, and low solar wind density (which correspond to high solar wind Alfvén velocity). IMF $B_{x}$ and solar wind pressure seem to have an only marginal influence.

During a survey of Polar UVI data, Kullen et al. (2002) found that at least $10 \%$ of the time some type of large-scale polar arc is present in the polar cap. Small-scale arcs (i.e., small splits), that are near the oval, but still visible to Polar UVI appear at least $6 \%$ of the time. Since the IMF is northward half of the time, and about $80 \%$ of the large-scale arcs appear during northward IMF, we would expect large-scale arcs to appear poleward of the main auroral oval at least 15 to $20 \%$ of the time during northward IMF.

In contrast to large-scale arcs, small-scale Sun-aligned arcs are seen about half the time during northward IMF (e.g., Lassen and Danielsen, 1978; Gussenhoven, 1982; Ismail and Meng, 1982). In a statistical study, Valladares et al. (1994) examined stable narrow Sun-aligned optical polar cap arcs viewed by all-sky imaging photometers. These arcs are about $100 \mathrm{~km}$ wide, extend $1000-2000 \mathrm{~km}$ in the sunward direction, and have an intensity range of about 50 to $1000 \mathrm{R}$, although most are $\sim 100 \mathrm{R}$. These arcs occur under similar IMF conditions as the moving arcs and the oval-aligned arcs 
discussed above and have a strong dependence on positive IMF $B_{z}$. The motion of these small-scale Sun-aligned arcs is controlled by IMF $B_{y}$ in the same way as large-scale transpolar arcs (Gusev and Troshichev, 1986; Cumnock et al., 1997; Kullen et al., 2002). It has been proposed that small-scale Sun-aligned arcs are embedded in polar rain and thus occur on open field lines (e.g., Carlson and Cowley, 2005, and references therein).

\subsection{Ionospheric convection during northward IMF}

The global polar ionospheric convection pattern during southward IMF consists of two cells with anti-sunward flow over the high-latitude region. However, for northward IMF there are a variety of configurations which result in sunward flow at highest latitudes. Averaged patterns that are derived from a large number of satellite passes include onecell or highly distorted two-cell patterns (Heppner and Maynard, 1987); modelled convection patterns result in one, three or four cells (Blomberg and Marklund, 1991). A statistical study of individual patterns (Cumnock et al., 1995) also observes the occurrence of one, three or four cell patterns. Individual satellite passes can exhibit more complex fine structure in cross-track flow and current sheets for which many flow shear structures coincide with current convergence characteristic of Ohm's law arcs such that the associated electric field has a negative gradient (Carlson et al., 1988). However, sometimes a steep negative gradient in the electric field occurs only at the edge of a wide region of arc precipitation (Obara et al., 1993). All of these northward IMF patterns result in sunward ionospheric plasma flow near the noonmidnight meridian but only for the four-cell pattern is sunward flow produced by two reverse convection cells at highest latitudes. The northward IMF patterns are generally characterized by lower convection velocities than the ionospheric convection during southward IMF and usually have smallscale structures in regions of lower conductivity (darkness) (Cumnock et al., 1995; Sundberg et al., 2009). These smallscale structures seen in individual passes occur in sunward flow which may be part of reverse convection cells. They may also be associated with small-scale Sun-aligned arcs (Nielsen et al., 1990) or theta aurora (Frank et al., 1986).

Marklund et al. (1991) found that convection signatures varied a lot along the transpolar arc, changing from sunward to anti-sunward flow depending on the relative importance of the arc-associated electric field. Sunward convection (and the associated field-aligned currents) was observed in the most intense segments of the arc. Marklund and Blomberg (1991) conducted event studies and idealized model studies in parallel, investigating various large and medium-scale phenomena associated with observed arc signatures and their influence on global electrodynamics, and found that transpolar arcs can be associated with sunward flow which may be reduced or enhanced depending on the current sheet configuration. In an event study, Liou et al. (2005) found that there was no consistent flow pattern within the dayside of the TPA, but always saw anti-sunward flow in the nightside of the TPA (for another example of anti-sunward flow on the nightside TPA, see Nielsen et al., 1990).

Blomberg and Marklund (1993) found that large-scale modifications to the polar convection pattern can be created either by transpolar arc related NBZ currents which are spatially extended or a spatially small arc related field-aligned current system carrying a significant net current. The effects of these two configurations are quite different. NBZ currents drive large-scale convection and often results in reverse convection cells at highest latitudes resulting in a four-cell pattern (for an example, see Cumnock and Blomberg, 2004). Smaller-scale transpolar arc related net currents have the effect of expanding the dusk (dawn) cell if the net current is upward (downward) so that the spatial extent of the cell is increased resulting in a two-cell pattern with one of the cells much larger than the other. In both cases sunward (or reduced anti-sunward) flow is located at high latitudes. Smallscale modifications may also take place either reversing the convection so that it is sunward locally, or introducing kinks and bends in the convection streamlines.

The main purpose of this paper is to investigate an interesting type of extremely high latitude aurora as identified by the Defense Meteorological Satellite Program's (DMSP) F13 satellite's SSJ/4 precipitating particle detector. In particular we investigate structures within large-scale arcs for which the particle signatures are made up of multiple distinct thin arcs, these cases are chosen without regard to IMF orientation. The multiple arc region is clearly separated from the auroral oval; thus it is likely that these arc groups belong to one of the large-scale arc categories discussed above. We analyze these cases and consider the precipitation, field-aligned currents (FACs), local convection signatures, and the global convection background associated with them and their correlation with solar wind conditions.

\section{Observations}

In the present study we identify extremely high latitude emissions measured by the DMSP F13 SSJ/4 particle detectors. DMSP F13 has a Sun-synchronous circular polar orbit where the satellite track is aligned along the dawn-dusk meridian. The SSJ/4 instrument package includes curved plate electrostatic analyzers to measure electrons and ions from $32 \mathrm{eV}$ to $30 \mathrm{keV}$ at a rate of one complete electron and ion spectrum per second resulting in a spatial resolution of about $7 \mathrm{~km}$. The satellite is three-axis stabilized and the detector apertures always point toward (local) zenith. This means that the observed fluxes are largely within the atmospheric loss cone. The instrument threshold for energy flux of ions is $10^{5} \mathrm{eV} / \mathrm{cm}^{2} \mathrm{~s}$ sr and for energy flux of electrons the threshold is approximately the same $\left(10^{4.68} \mathrm{eV} / \mathrm{cm}^{2} \mathrm{~s} \mathrm{sr}\right)$. However, for individual cases the counting statistics may be poor for 
F13 5 Jan 1997

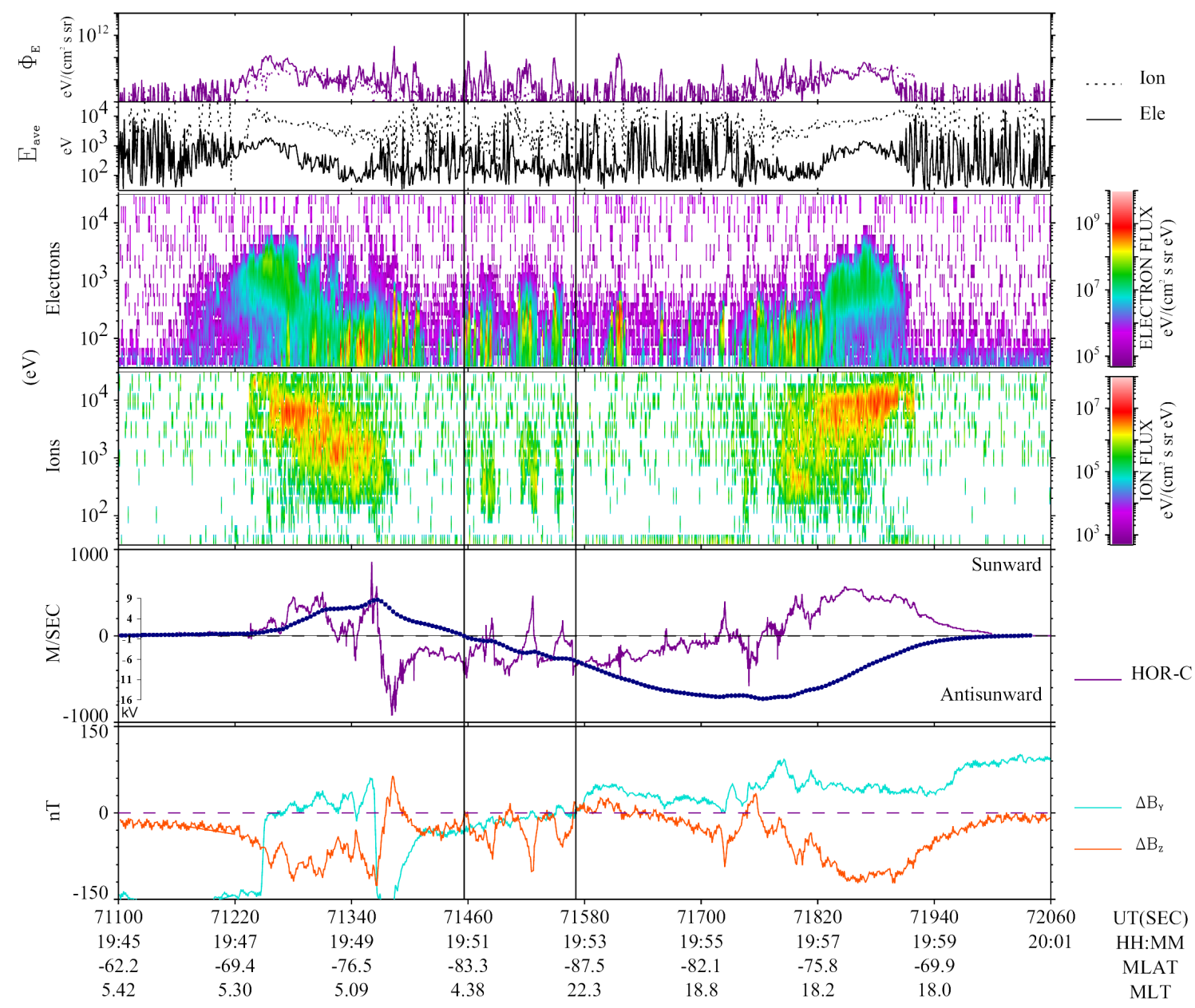

Fig. 1. DMSP F13 polar pass taken on 5 January 1997 in the sunlit Southern Hemisphere. The satellite track is on the nightside of the dawn-dusk meridian and the highest magnetic latitude reached is 87 degrees. Because of the orbit geometry, dawn is on the left hand side and dusk is on the right. The F13 spectrograms include, from top to bottom, (1) electron and ion integral energy flux, (2) electron and ion average energy, (3) electron differential energy flux spectrogram, (4) ion differential energy flux spectrogram, (5) cross-track horizontal plasma drift and along-track electrostatic potential distribution (blue line), (6) $\Delta B_{y}$ (along track, blue line) and $\Delta B_{z}$ (sunward, red line). Note that the flux scales are different for the electron and ion spectrograms.

ions. The special sensor for ions, electrons, and scintillation (SSIES) provides measurements of the horizontal plasma flow and ion density at a rate of 6 samples per second. The electrostatic potential distribution is derived by integrating the electric field $(\boldsymbol{E})$ along the satellite track, using $\boldsymbol{E}=-\boldsymbol{v} \times \boldsymbol{B}$, where $\boldsymbol{v}$ is the measured transverse ion drift velocity and $\boldsymbol{B}$ is the model geomagnetic field. The electrostatic potential can then be used to determine which regions of sunward and antisunward flow may be connected by equipotential flow lines. The Special Sensor Magnetometer (SSM), a triaxial fluxgate magnetometer, provides magnetic field component measurements in the satellite $\mathrm{X}$ (down), $\mathrm{Y}$ (along-track forward), and $\mathrm{Z}$ (cross-track, anti-parallel to the orbit normal) directions. The $\Delta B_{z}$ component can be used to estimate field-aligned currents assuming current sheets are oriented approximately perpendicular to the satellite track. Negative slope in $\Delta B_{z}$ corresponds to upward current and positive slope to downward current. Because of the orbital geometry dawn is on the left hand side for Southern Hemisphere passes (Figs. 1 and 2) and dusk is on the left hand side for Northern Hemisphere passes (Figs. 3 and 4).

We consider only passes where the satellite track reaches at least 88 degrees magnetic latitude on the dayside or 86 degrees on the nightside of the geomagnetic poles. About 6000 passes out of approximately 30000 total Northern and Southern Hemisphere polar passes for a 3-year period (19961998) are within this region. We then identify particle precipitation signatures which occur at or above 87 degrees 
F13 5 Jan 1997

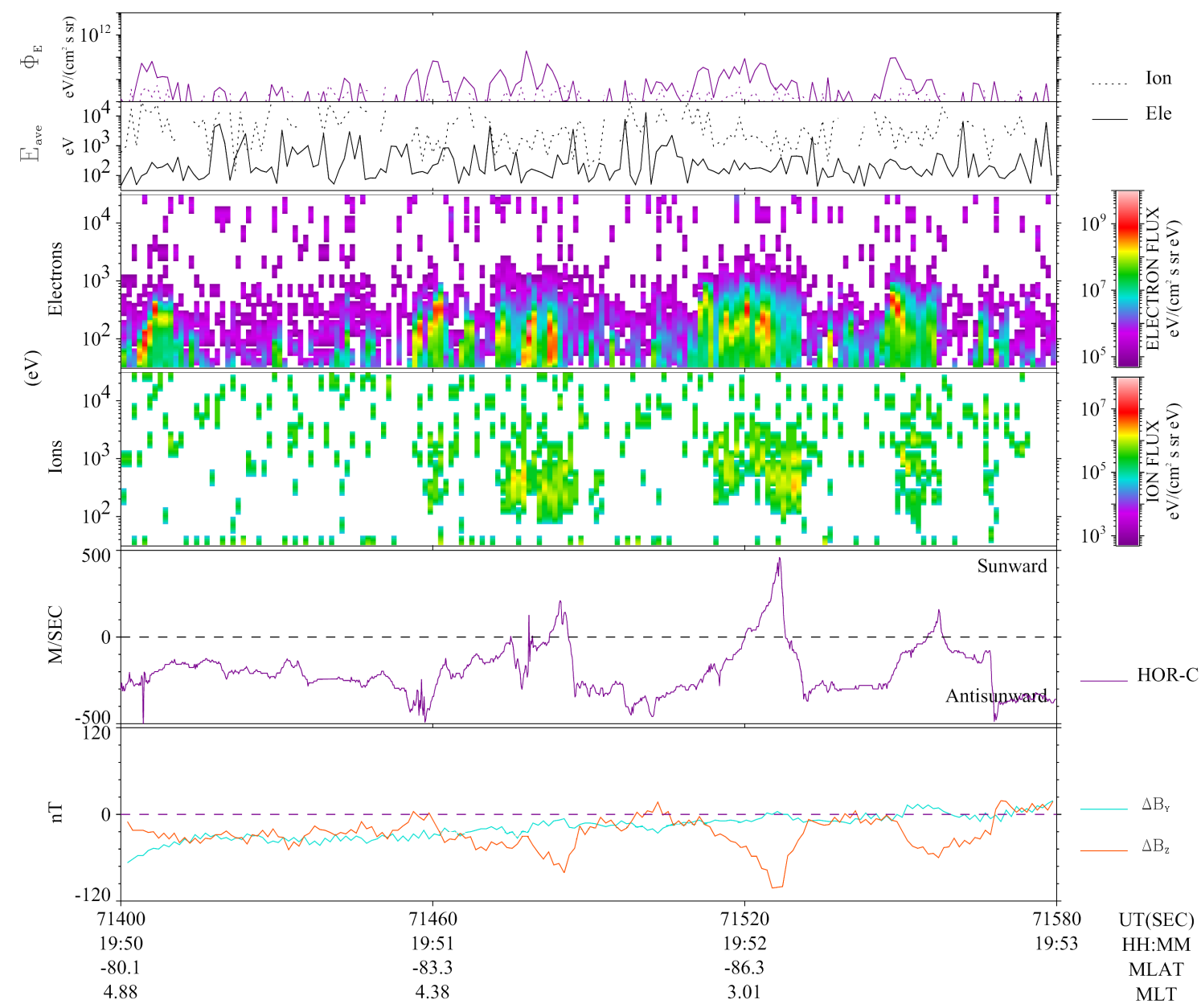

Fig. 2. Plot of a three minute interval from Fig. 1 which includes the high-latitude arcs.

magnetic latitude seen as the satellite moves in the duskto-dawn (dawn-to-dusk) direction in the Northern (Southern) Hemisphere. This results in a total of 346 events in both the Northern and Southern Hemispheres. The events are selected without regard to IMF orientation.

For 87 of the 346 events particle precipitation signatures occur near the noon-midnight meridian and are spatially separated from both the dawnside and duskside auroral ovals by approximately 450 to $1800 \mathrm{~km}$. Thus while about $6 \%$ of the time auroral emissions are seen at extremely high latitudes, only $1.5 \%$ of the time are isolated arcs observed. These arcs vary in spatial width and small-scale characteristics. For 14 of the 87 events the particle signatures are made up of multiple distinct thin arcs. The regions encompassing the thin arcs range in spatial width from 490 to $1070 \mathrm{~km}$; within these regions both the distinct arcs and regions without particle precipitation range from about 50 to $150 \mathrm{~km}$. We look at these special cases and consider the precipitation, field-aligned currents, local convection signatures, and the global convec- tion background associated with the multiple thin arcs. Using only DMSP SSJ/4 precipitating particle measurements we cannot tell which type of large-scale high-latitude arc is observed.

Figure 5 shows Polar UV images from 24 November 1998 and includes the time period of the DMSP pass seen in Figs. 3 and 4. In the Lyman-Birge-Hopfield long mode (LBHl) the instrument measured molecular nitrogen emissions in the $160-180 \mathrm{~nm}$ spectral region with a detection threshold of $\sim 15 \mathrm{R}$, and produced 36-s integration period images in the Northern Hemisphere. The UV figure shows the development of a duskside oval-aligned substorm recovery arc; unfortunately the post-noon oval is not in the instrument field of view. The top left panel shows that the dusk oval has expanded to slightly higher latitudes than the dawn oval and an oval-aligned arc has begun to separate from the duskside auroral oval. The second image (taken at 19:16 UT) shows measurements taken at the same time as Figs. 3 and 4 and one can clearly see emissions on the duskside of the 


\section{F13 24 Nov 1998}

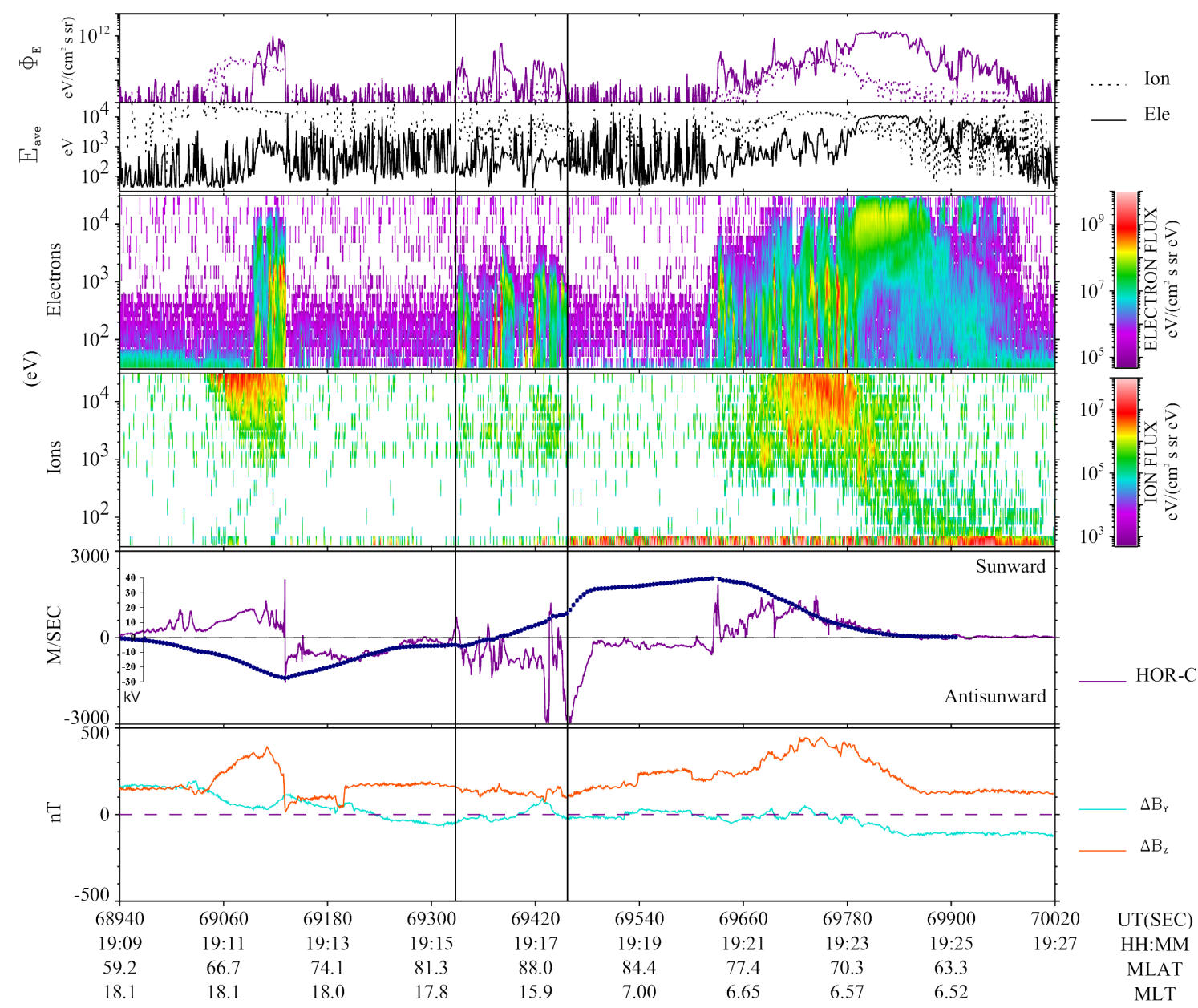

Fig. 3. DMSP F13 polar pass taken on 24 November 1998 in the dark Northern Hemisphere; same format as Fig. 1 except that because of the orbit geometry dusk is on the left hand side and dawn on the right. The satellite track is just 1 degree to the dayside of the dawn-dusk meridian and reaches 89 degrees magnetic latitude at the noon-midnight meridian. Same time as Fig. 5, second image.

noon-midnight meridian and along the DMSP F13 satellite track, which reaches 89 degrees magnetic latitude at the noon-midnight meridian and is on the dayside of the dawndusk meridian. The part of the polar region duskward of the high-latitude emissions is not in the Polar UV instrument field of view but we know from the DMSP measurements (Fig. 3) that along the dawn-dusk meridian the duskside oval is quite narrow. As the substorm recovery arc evolves the nightside portion of the arc moves toward the noon-midnight meridian and fades (images 3 and 4). The UV imager does not have the resolution to identify the small-scale arcs seen in the DMSP SSJ/4 precipitating particle measurements. The UV instrument is only able to resolve 0.5 degrees in latitude at apogee; thus, a single pixel projected to $100 \mathrm{~km}$ altitude is approximately $50 \times 50 \mathrm{~km}$ which is larger than some of the thin arcs. In addition spacecraft wobble can cause this projection to be $50 \times 250 \mathrm{~km}$.

\section{Results and discussion}

In order to examine solar wind conditions during highlatitude aurora events we use the near continuous $5 \mathrm{~min}$ averaged measurements provided by the OMNIWeb data set (http://omniweb.gsfc.nasa.gov). The data set consists of measurements from the solar wind monitor (WIND, IMP-8, Geotail or ACE) which is closest to the Earth's bow shock. The data are propagated in time to correspond to the solar wind conditions at the bow shock. An additional 10$15 \mathrm{~min}$ propagation time is expected for the solar wind to begin affecting the ionosphere. We use a $30 \mathrm{~min}$ average of the solar wind parameters beginning one hour prior to when the DMSP satellite crosses the high-latitude emission region (which coincides with the highest latitude crossed by the satellite). We measure the change in IMF $B_{y}$ (increase or decrease) nearest the DMSP measurements, usually within 


$$
\text { F13 } 24 \text { Nov } 1998
$$

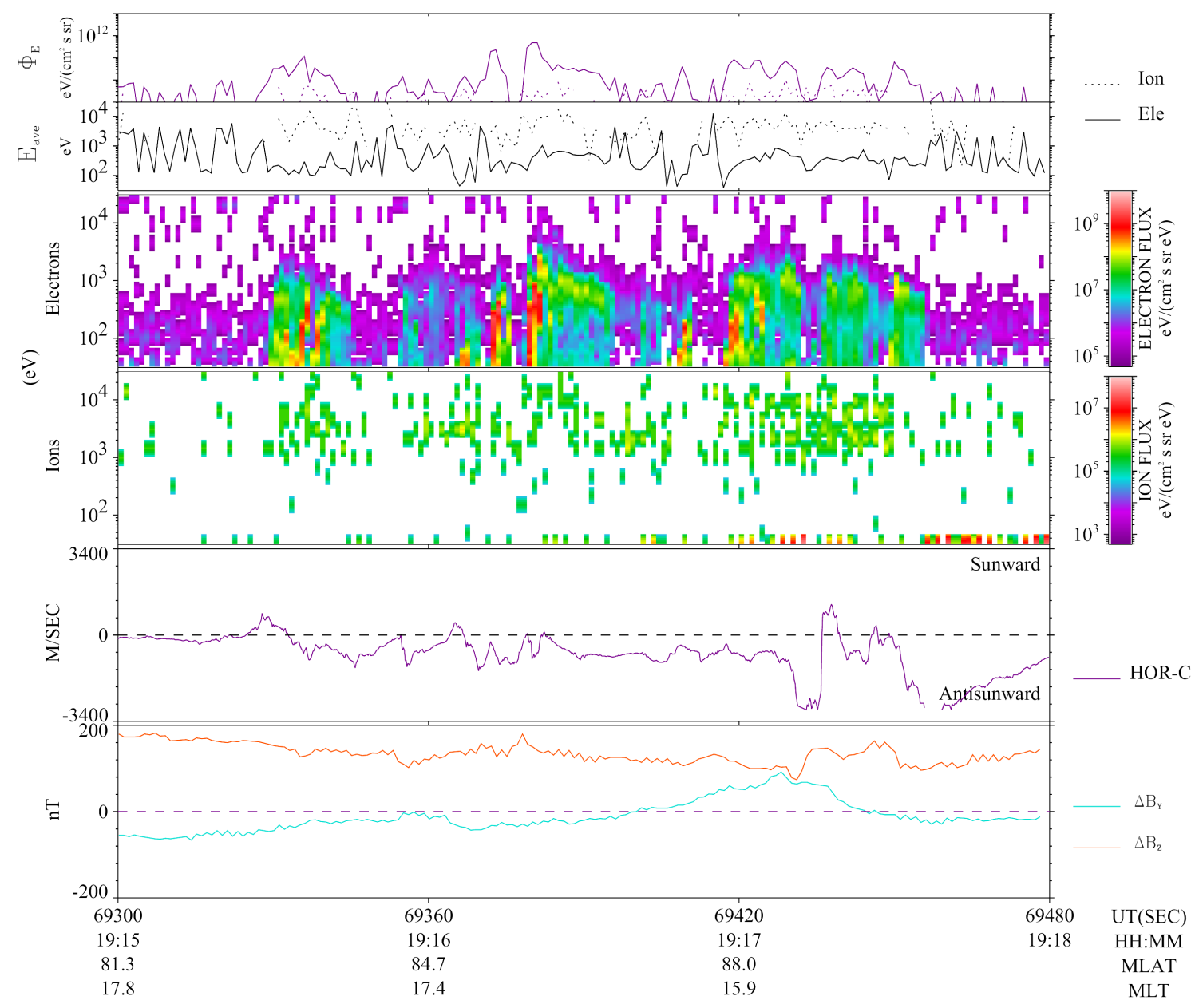

Fig. 4. Plot of a three minute interval from Fig. 3 which includes the high-latitude arcs.

1-2 h. All but two of the events have actual $B_{y}$ sign changes associated with them. In the Northern Hemisphere negative IMF $B_{x}$ and positive Earth dipole tilt during northward IMF provide favourable conditions for anti-parallel merging between the IMF and Earth's magnetic field lines (i.e., lobe reconnection) (Crooker, 1979) which has been observed to have an influence on TPA occurrence (Kullen et al., 2002) and NBZ current density (Iijima et al., 1984). Positive dipole tilt also indicates that at least part of the Northern Hemisphere is sunlit. Since the opposite is true for the Southern Hemisphere the sign of IMF $B_{x}$ and dipole tilt were changed for the Southern Hemisphere events in order to directly compare events from both hemispheres. Also, IMF $B_{y}$ controls the formation and motion of transpolar arcs; in the Northern Hemisphere negative (positive) $B_{y}$ results in arc formation on the dawn (dusk) side of the auroral oval and as $B_{y}$ increases (decreases) the TPA may move across the polar region in the dusk (dawn) direction (Cumnock et al., 1997). Since the opposite relation is true in the Southern Hemisphere (e.g., Cum- nock et al., 2006), we also adjust the sign of IMF $B_{y}$ in order to directly compare events from both hemispheres.

Figure 6 shows IMF $B_{x}$ versus Earth dipole tilt for all 87 events. The blue diamonds denote the 73 single arc events and the pink squares denote the 14 events with multiple distinct thin arcs. The single arcs are those with a near continuous region of precipitating particles although there are still variations in the precipitating particle integral energy flux. The single arcs are narrower (most have a width between 100 and $600 \mathrm{~km}$ ), while the regions containing multiple arcs are wider (most between 700 and $1070 \mathrm{~km}$ ). The multiple arcs are separated by narrow regions of downward current which have low particle fluxes. The multiple arcs are also separated by minimums in the electron energy flux that are less than $2 \times 10^{6} \mathrm{eV} / \mathrm{cm}^{2} \mathrm{~s} \mathrm{sr}$, with some near zero. Electron energy flux minimums for the single arcs are well above this number.

Some differences and similarities between the two categories are readily apparent in Fig. 6. Whereas about half of 


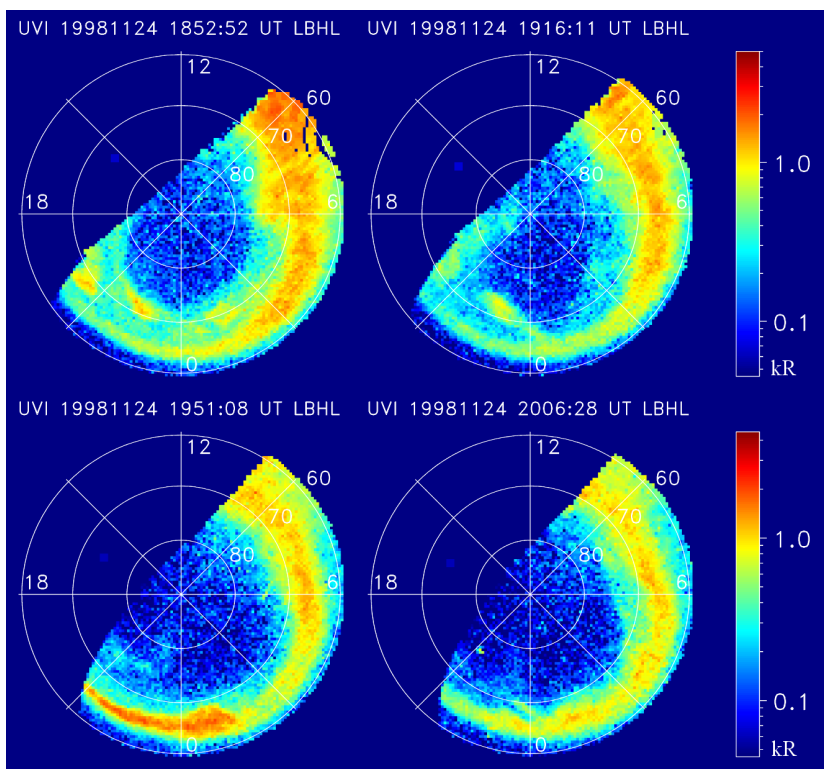

Fig. 5. Polar UV images taken in the LBH long mode for the 24 November 1998 oval-aligned substorm recovery arc (same event as DMSP data shown in Figs. 3 and 4). The DMSP F13 satellite track reaches 89 degrees magnetic latitude at the noon-midnight meridian and is on the dayside of the dawn-dusk meridian.

the multiple distinct thin arcs occur in the dark hemisphere (negative dipole tilt), most of the single arcs occur in the sunlit hemisphere (positive dipole tilt). For both types just over half occur during conditions which favour anti-parallel merging (negative IMF $B_{x}$ and positive dipole tilt). Nearly all of the 14 multiple arc events occur during small Earth dipole tilts (smaller than $14 \mathrm{deg}$ ), whereas almost half of the single arcs occur for dipole tilt greater than 14 degrees (in regions of increasing illumination and conductivity).

Figure 7 shows IMF $B_{z}$ (pink squares) and the direction and magnitude of a change in IMF $B_{y}$ (blue diamonds) versus Earth dipole tilt for the 14 multiple distinct thin arc events. All of the events occur for northward or weakly southward (greater than $-2 \mathrm{nT}$ ) IMF. All but two of the events correspond to actual sign changes in $B_{y}$. Eight of the events occur for negative changes in IMF $B_{y}$. The width of the multiple arc region (not shown) ranges between about 490 and $1070 \mathrm{~km}$ (with 8 multiple arc regions wider than $700 \mathrm{~km}$ ) and the number of distinct thin arcs ranges from three to nine. There is a tendency for the width of the arc region in all 14 events to be greater for negative changes in IMF $B_{y}$. In addition, the correlation with negative changes in IMF $B_{y}$ is higher for slower changes and lower for faster changes. With so few events we cannot make a strong claim for this last correlation; however, the result is consistent with model predictions for single transpolar arcs, where a slower change in IMF $B_{y}$ results in a wider region of closed field lines inside the polar cap (Kullen, 2000; Kullen and Janhunen, 2004). In addition, the DMSP precipitating particles measured along the one-dimensional dawn-dusk satellite tra- jectory are presumed to be in a two-dimensional current sheet extending perpendicular to the satellite track since the arcs generally extend parallel to the noon-midnight meridian (as seen in Polar UV images).

Polar UV images taken in the Northern Hemisphere are available during the same time as eight of the DMSP events. For five cases DMSP measurements are also in the Northern Hemisphere; the other three DMSP passes are in the opposite (Southern) hemisphere. Those Polar UV images seen in the same hemisphere are consistent with DMSP observations; four are broad transpolar arcs (i.e., theta aurora) and one is an oval-aligned substorm recovery arc (see Fig. 5). However, Polar UVI does not have the resolution to show the small-scale arcs seen in the DMSP precipitating particles. The UV image taken in the opposite hemisphere but at the same time as the DMSP case seen in Figs. 1 and 2 shows a very thin theta aurora in the opposite (Northern) hemisphere. In this case IMF $B_{x}$ is steady and positive thus the winter Northern Hemisphere is not favoured for antiparallel merging. For the second case with Polar UV images in the opposite hemisphere, there are two wide transpolar arcs in the opposite sunlit (Northern) hemisphere; also here, IMF $B_{x}$ is positive and does not favour anti-parallel merging in the Northern Hemisphere. However, there were previous $B_{y}$ sign changes (at about 16 and 17 UT) which may have resulted in the formation of two arcs, one on each side of the auroral oval. The third case shows a substorm recovery arc located on the duskside of the polar region in the Northern Hemisphere. The substorm recovery arc is not expected because the IMF has been steady northward for over six hours and substorm activity is normally associated with southward IMF. A possible substorm trigger is the rotation of IMF $B_{y}$ from positive to negative about an hour before the DMSP observation. For the remaining six events global UV data are not available.

Examples of entire polar passes in both sunlit and dark conditions are shown in Figs. 1 and 3, respectively. Vertical black lines mark the multiple distinct thin arc regions. Figures 2 and 4 show details of the high-latitude arcs in Figs. 1 and 3, respectively. The F13 spectrograms include, from top to bottom, (1) electron and ion integral energy flux, (2) electron and ion average energy, (3) electron differential energy flux spectrogram, (4) ion differential energy flux spectrogram, (5) cross-track horizontal plasma drift and along-track electrostatic potential distribution (blue line), (6) $\Delta B_{y}$ (along track, blue line) and $\Delta B_{z}$ (sunward, red line).

Figure 1 (sunlit example) shows DMSP F13 satellite measurements taken from 19:45 to 20:01 UT on 5 January 1997 in the Southern Hemisphere. The satellite track is on the nightside of the dawn-dusk meridian and the highest magnetic latitude reached is 87 degrees. Because of the orbit geometry, dawn is on the left hand side and dusk on the right. For this case, the IMF is weakly northward, $B_{y}$ is near zero after a small decrease and $B_{x}$ is positive. Solar wind density is about $15 \mathrm{~cm}^{-3}$ and velocity $330 \mathrm{~km} / \mathrm{s}$. 


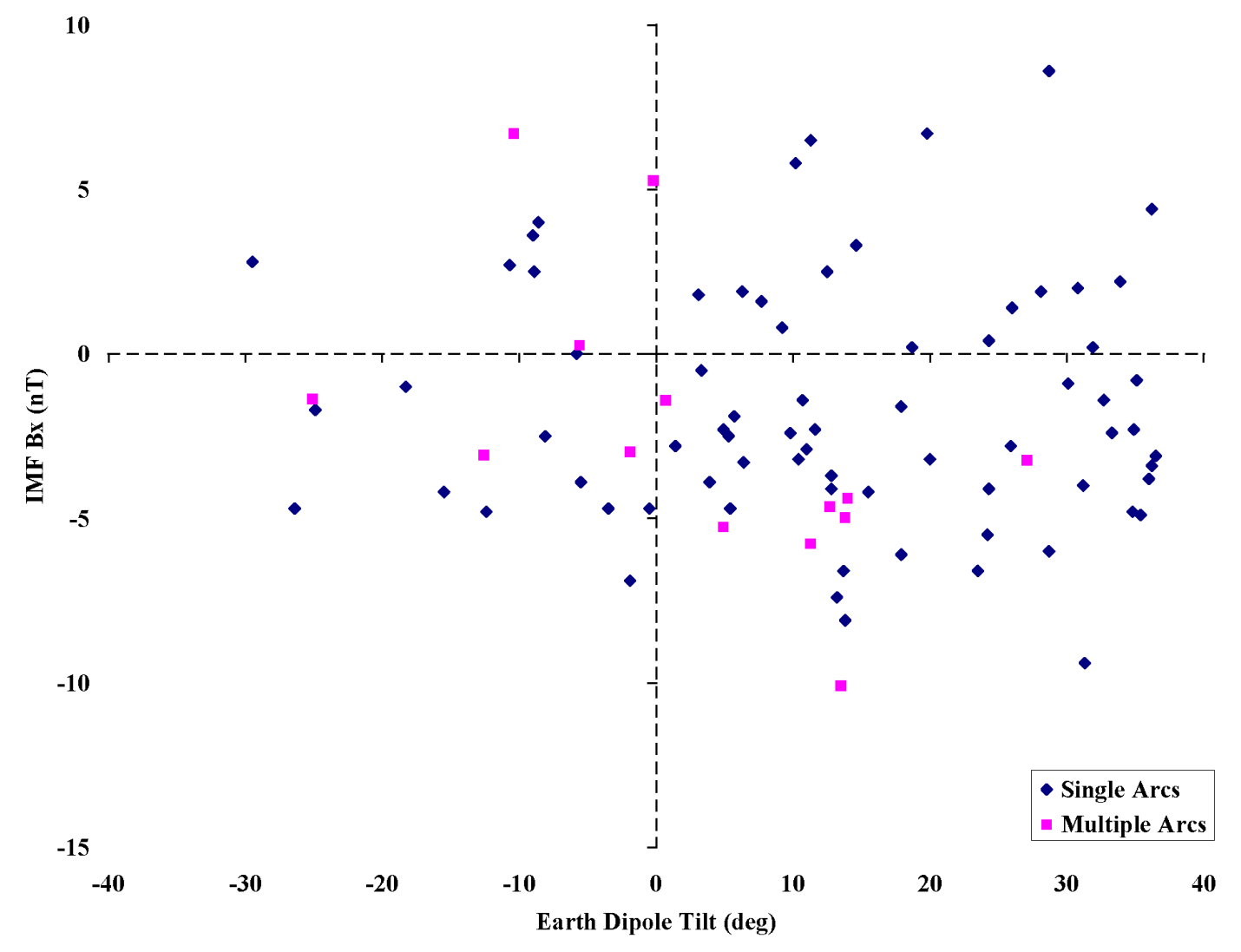

Fig. 6. IMF $B_{x}$ versus Earth dipole tilt for single arcs and multiple distinct thin arcs.

The electron and ion energy spectrograms show the overall emission pattern. Both the dawn and dusk sides of the auroral oval are clearly seen (left and right sides, respectively). The auroral oval is about the same spatial width on both sides which is in agreement with small IMF $B_{y}$ (Hones et al., 1989). The region of thin arcs (marked by vertical lines) is seen just dawnward of the noon-midnight meridian and is about $840 \mathrm{~km}$ wide. The peak integral energy fluxes (panel 1) associated with the arcs are about the same as those seen in the poleward edge of the auroral oval for the electrons $\left(\sim 10^{9} \mathrm{eV} / \mathrm{cm}^{2} \mathrm{~s} \mathrm{sr}\right)$, but lower for the ions $\left(\sim 10^{6.5} \mathrm{eV} / \mathrm{cm}^{2} \mathrm{~s}\right.$ sr for the arcs and $\sim 10^{7}$ for the oval). Both electrons and ions are well defined and have structure in them (panels 3 and 4). We clearly see the Region 1 and 2 current systems in the $\Delta B_{z}$ plot (panel 6) corresponding to the dawn and dusk side ovals.

The dawn and dusk sides of the auroral oval are co-located with sunward flow regions, this occurs for both northward and southward IMF. These regions of sunward flow are separated by a spatially large region of anti-sunward flow, however on this background pattern there are superposed local regions of sunward flow (or reduced anti-sunward flow). These small-scale sunward flow regions are associated with multiple thin arcs (marked by vertical lines) (see also Fig. 2). The electrostatic potential distribution shows that most of the ionospheric plasma flow can be closed as a negative potential cell shifted to the duskside and encompassing the region of thin arcs. The zero potential point is located just dawnward of the group of arcs and denotes the dividing line between the convection cells. This Southern Hemisphere convection pattern is consistent with the IMF observations (Heppner and Maynard, 1987; Cumnock et al., 1995); that is weakly northward IMF $B_{z}$ and weakly negative IMF $B_{y}$ which results in a spatially larger (negative potential, $\min =-16 \mathrm{kV}$ ) clockwise rotating dusk cell which dominates the polar region and a smaller (positive potential, $\max =9 \mathrm{kV}$ ) counter-clockwise rotating dawn cell confined to lower latitudes. The convection associated with the multiple thin arcs is localized and has little influence on the large-scale convection/electrostatic potential patterns. This also implies that the sunward flow (or reduced anti-sunward flow) along the arcs is unrelated to the overall ionospheric convection.

Figure 2 shows that there is in general good correlation between the precipitating electrons and ions, the sunward plasma flows, and $\Delta B_{z}$. There are three main pairs of FACs corresponding to each of the three general regions of particle precipitation and sunward plasma flow. Electrons and ions are generally co-located except that the integral energy fluxes are higher for electrons in regions of upward FACs and higher for ions in regions of downward FACs (this also 


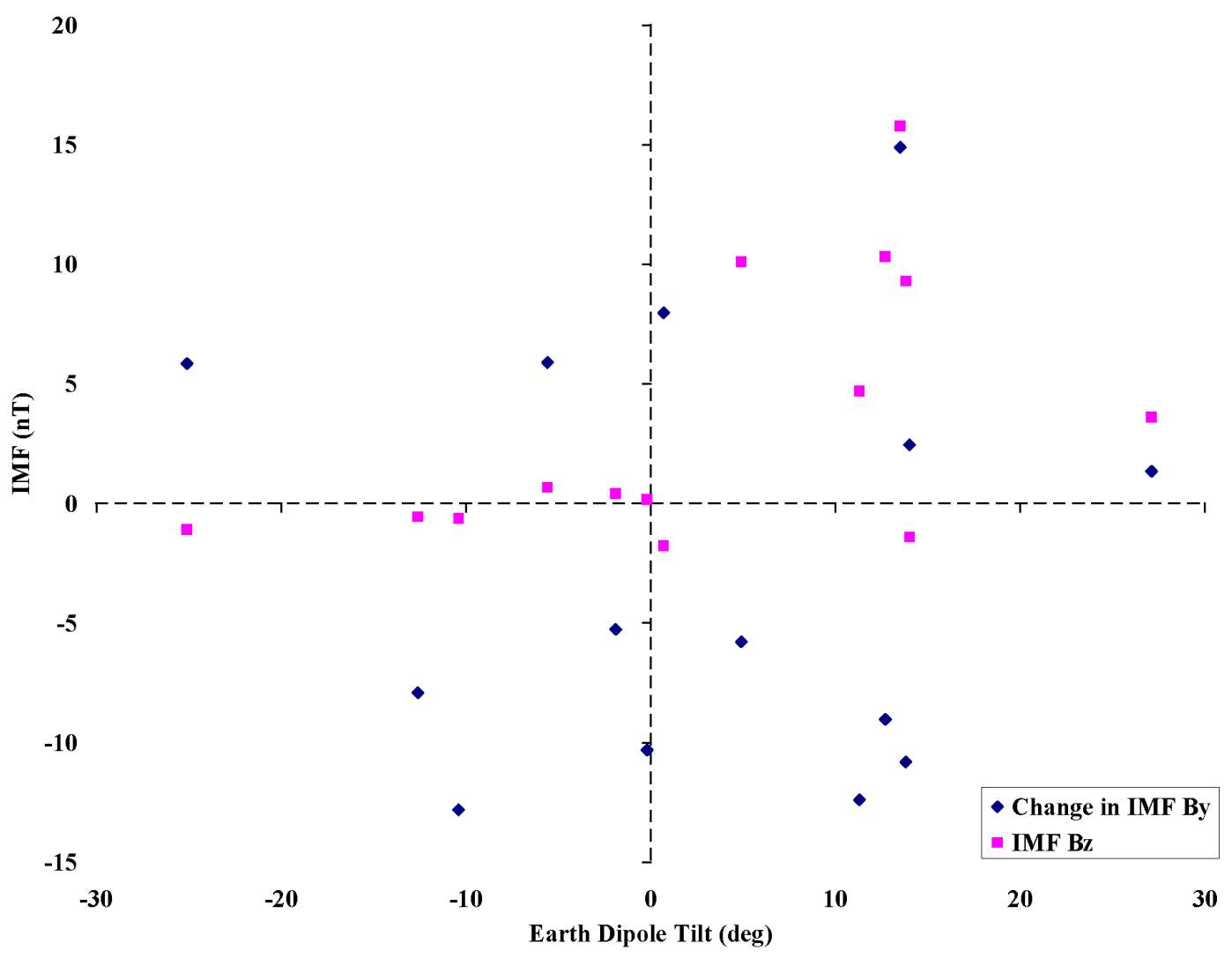

Fig. 7. IMF $B_{z}$ and direction and magnitude of a change in IMF $B_{y}$ versus Earth dipole tilt for the multiple thin arc events.

holds for currents on a smaller scale). These three pairs of currents are interpreted as current sheets with an upward current on the dawnside and a downward current on the duskside. The lack of variation in $\Delta B_{y}$ confirms that the FACs may be approximated by current sheets and the strong correlation with the plasma flow (or equivalently, with the horizontal electric field in the ionosphere) implies that the FACs close locally via Pedersen currents in the conducting ionosphere (e.g., Sugiura, 1984).

Figure 3 (darkness example) shows DMSP F13 satellite measurements taken on 24 November 1998 in the Northern Hemisphere from 19:09 to 19:29 UT. The satellite track is just to the dayside of the dawn-dusk meridian and the highest magnetic latitude reached is 89 degrees. Same format as Fig. 1 except that because of the orbit geometry dusk is on the left hand side and dawn on the right. For this case, IMF $B_{z}$ is near zero, $B_{y}$ recently had a sign change of $-13 \mathrm{nT}$, and $B_{x}$ is positive. Solar wind density is about $5 \mathrm{~cm}^{-3}$ and velocity $450 \mathrm{~km} / \mathrm{s}$.

Compared to the event shown in Fig. 1, Fig. 3 shows some overall differences in the electron and ion spectrograms. The duskside aurora is much more narrow and the dawnside auroral oval is much wider (left and right sides, respectively). This difference can partially be attributed to a difference in the IMF. For 24 November 1998, IMF $B_{y}$ is negative and its magnitude is much larger than the magnitude of $B_{z}$ which results in the dawnside auroral oval expanding poleward. The region of thin arcs (marked by vertical lines) is located just duskward of the noon-midnight meridian and is about $950 \mathrm{~km}$ wide. The peak integral energy fluxes (panel 1) associated with the arcs are about the same as those seen in the poleward part of the auroral oval for the electrons $\left(\sim 10^{9} \mathrm{eV} / \mathrm{cm}^{2} \mathrm{~s} \mathrm{sr}\right)$, but are lower for the ions $\left(\sim 10^{6.5} \mathrm{eV} / \mathrm{cm}^{2} \mathrm{~s}\right.$ sr for the arcs and $\sim 10^{7}$ for the oval). The energy spectrograms show that the ion precipitation is much less structured and defined than the electrons. In this pass the Region 1 and 2 current systems in the $\Delta B_{z}$ plot (panel 6) are very clearly seen; while the signatures corresponding to the high-latitude regions of multiple thin arc particle precipitation are not as clear as in the sunlit pass. This is not surprising since lower conductivity in the dark hemisphere results in much weaker FACs than those seen in the sunlit hemisphere event.

The ionospheric convection for this event is similar to the sunlit pass; where regions of sunward flow are separated by a spatially large region of anti-sunward flow. Also, on this background pattern there are superposed local regions of sunward flow (or reduced anti-sunward flow) associated with multiple thin arcs (marked by vertical lines). However, compared to the sunlit example, the sunward flow is much 
more structured and the arcs are not clearly coincident with regions of sunward flow (see Fig. 4). The electrostatic potential distribution shows that much of the ionospheric plasma flow may be closed as a positive potential counterclockwise rotating cell shifted to the dawnside; a smaller clockwise rotating cell is located on the duskside. In this case the region of thin arcs is encompassed by the positive potential cell. This Northern Hemisphere convection pattern is consistent with what is expected for the corresponding IMF observations, that is near zero IMF $B_{z}$ and an IMF $B_{y}$ which has recently changed from positive to negative which results in a decreasing dusk cell and an increasing dawn cell. The maximum and minimum potentials $(40$ and $-27 \mathrm{kV}$, respectively) are much larger than the previous example and can be attributed to a higher solar wind velocity and higher IMF magnitude $\left(\mathrm{vB}^{2}\right.$ is four times higher than in the previous example).

Figure 4 shows that, in contrast to the sunlit example, there is very little correlation between the precipitating particles, the plasma flows and $\Delta B_{z}$. Variations in $\Delta B_{z}$ associated with the multiple thin arcs are only about $50 \mathrm{nT}$ compared with 60-90 nT for the sunlit example. Even so, integral energy fluxes are higher for electrons in regions of upward FACs and higher for ions in regions of downward FACs. Note that the flux scales are different for the electron and ion spectrograms. The variation in $\Delta B_{y}$ at about 19:17 UT implies that the current is not organized in a Sun-aligned current sheet.

Whereas the width of the multiple thin distinct arc regions range between 490 and $1070 \mathrm{~km}$ the individual thin arcs vary in width from about 50 to $150 \mathrm{~km}$ with similar widths of the gaps in between the thin arcs. From a satellite view point (depending on resolution at ionospheric altitude) these thin arc regions may look like a single arc thus further complicating their analysis. From a ground based point of view these arcs may look similar to those analyzed by Valladares et al. (1994) (see for example their Fig. 2a and b). Whereas the small-scale arcs viewed by Valladares are much more common during northward IMF (occurring 50\% of the time) and are normally associated with open field lines, the width $(\sim 100 \mathrm{~km})$ and intensities (50 R to $1 \mathrm{kR})$ are similar to those we observe here. Our winter example has brightest emissions of $\sim 500 \mathrm{R}$ (see Fig. 5), which is a typical value for theta aurora observed by Polar UVI in the winter hemisphere under steady northward IMF conditions. They also form under similar IMF conditions as those discussed in this paper and with the moving arcs and oval-aligned arcs discussed above. They have a strong dependence on positive IMF $B_{z}$ and the motion of the small-scale Sun-aligned arcs is controlled by IMF $B_{y}$ in the same way as large-scale transpolar arcs. Thus, some overlap in these categories cannot be ruled out without multiple ground and space based observations of sufficient resolution.

We also see differences between sunlit and dark hemisphere observations in the large-scale ionospheric convection. For all the sunlit hemisphere cases the multiple distinct thin arcs region is associated with a large-scale sunward flow region, except the sunlit case shown in Fig. 1 where the sunward flow is embedded in an anti-sunward flow region. In all the dark hemisphere cases the arc region is associated with reduced anti-sunward flow embedded in a large-scale antisunward flow region. Only three of the 14 cases have reverse convection at highest latitudes as part of a four-cell pattern and all of them occur in the sunlit hemisphere. The reverse convection cases are the only events where the thin arc regions have large-scale NBZ currents. These NBZ currents drive the large-scale reverse convection. In the other cases, only small-scale modifications take place, either enhancing the sunward convection or reversing the convection so that it is sunward locally. In both cases shown the multiple thin arc region is co-located with sunward (or reduced anti-sunward) flow and is located at the high latitude edge of a spatially large convection cell and may act to influence the spatial extent of the convection cell but not change the overall pattern.

We expect that the same mechanism (or magnetospheric topology) is present for the groups of thin arcs as for the single arcs since they seem to form under similar IMF conditions. The question as to what causes multiple distinct thin arcs vs. single arcs remains for future work.

\section{Summary and conclusions}

In this paper we have examined an interesting type of extremely high latitude aurora made up of multiple distinct thin arcs. These events vary in width and small-scale characteristics. The UV images show that they fit into already observed categories of large-scale high-latitude auroral arcs however their characteristic width is greater than single arcs (consisting of a more continuous precipitating particle signature).

All of the 14 multiple distinct thin arc events occur during northward or weakly southward IMF conditions and follow a change in IMF $B_{y}$. They occur in both sunlit and dark hemispheres and do not have a dependence on IMF $B_{x}$.

All but two occur for small Earth dipole tilt (smaller than $14 \mathrm{deg}$ ). Thus, there is a clear dependence on dipole tilt angle which is different from that for single arcs that occur predominantly in the sunlit hemisphere (positive dipole tilt).

In general, for quiet times the auroral particle fluxes and the luminosity of extremely high latitude aurora are comparable to the quiet-time auroral oval. We find that electron fluxes are similar in both sunlit and dark hemispheres; however ion fluxes tend to be lower in the dark hemisphere.

Correlations are seen between the field-aligned currents and plasma flows associated with the multiple distinct thin arcs, implying local closure of the FACs. Strong correlations are seen only in the sunlit hemisphere. Small-scale arcs are embedded in the large-scale convection pattern. The convection associated with the multiple thin arcs is localized and has little influence on the large-scale convection but may act 
to influence the spatial extent of a particular ionospheric convection cell.

In general the ionospheric convection patterns are consistent with northward or weakly southward IMF conditions, with only three of the 14 events showing two-cell patterns; the others are one-cell dominant, three or four-cell patterns. Most of the events which occur in darkness have some smallscale structure; however the overall patterns are readily identifiable. All of the four-cell ionospheric convection patterns occur for passes in sunlit conditions. In addition, in all but one of the sunlit passes the arcs are co-located with sunward ionospheric plasma flow.

Analysis of the ionospheric convection patterns, precipitating particles, and field-aligned currents measured by the DMSP satellite in both hemispheres and their relation to the extremely high latitude aurora is ongoing.

Acknowledgements. The authors thank George Parks and the Polar UVI team for providing UV images, as well as the ACE, IMP-8, and Wind instrument teams for providing magnetometer and plasma data through the GSFC/SPDF OMNIWeb interface at http://omniweb.gsfc.nasa.gov. Work at the University of Texas at Dallas was supported by NSF grant ATM0536868. The DMSP particle detectors were designed by Dave Hardy of AFRL, and data obtained from JHU/APL. We thank Dave Hardy, Fred Rich, and Patrick Newell for their use. We gratefully acknowledge the William B. Hanson Center for Space Sciences at the University of Texas at Dallas for providing the DMSP thermal plasma data.

Topical Editor M. Pinnock thanks H. C. Carlson and another anonymous referee for their help in evaluating this paper.

\section{References}

Blomberg, L. G. and Marklund, G. T.: High-latitude convection patterns for various large-scale field-aligned current configurations, Geophys. Res. Lett., 18, 717-720, 1991.

Blomberg, L. G. and Marklund, G. T.: High-latitude electrodynamics and aurorae during northward IMF, in Auroral Plasma Dynamics, Geophys. Monogr. Ser., vol. 80, edited by: Lysak, R. L., pp. 55-68, AGU, Washington, D.C., 1993.

Bonnell, J., Elphic, R. C., Palfery, S., Strangeway, R. J., Peterson, W. K., Klumpar, D., Carlson, C. W., Ergun, R. E., and McFadden, J. P.: Observations of polar cap arcs on FAST, J. Geophys. Res., 104(A6), 12669-12681, 1999.

Brittnacher, M., Fillingim, M., Parks, G., Germany, G., and Spann, J.: Polar cap area and boundary motion during substorms, J. Geophys. Res., 104(A6), 12251-12262, 1999.

Carlson, H. C., Heelis, R. A., Weber, E. J., and Sharber, J. R.: Coherent Mesoscale Convection Patterns During Northward Interplanetary Magnetic Field, J. Geophys. Res., 93, 14501-14514, 1988.

Carlson, H. C. and Cowley, S. W. H.: Accelerated polar rain electrons as the signature of sun-aligned arcs in the polar cap during northward IMF conditions, J. Geophys. Res., 110, A05302, doi:10.1029/2004JA010669, 2005.

Chang, S.-W., Scudder, J. D., Sigwarth, J. B., Frank, L. A., Maynard, N. C., Burke, W. J., Peterson, W. K., Shelley, E. G., Friedel, R., Blake, J. B., Greenwald, R. A., Lepping, R. P., Sofko, G.
J., Villain, J.-P., and Lester, M.: A comparison of a model for the theta aurora with observations from Polar, Wind, and SuperDARN, J. Geophys. Res., 103, 17367-17390, 1998.

Craven, J. D., Frank, L. A., Russell, C. T., Smith, E. J., and Lepping, R. P.: Global auroral responses to magnetospheric compressions by shocks in the solar wind: Two case studies, in Solar WindMagnetosphere Coupling, edited by: Kamide, Y. and Slavin, J. A., pp. 367, Terra Sci., Tokyo, 1986.

Craven, J. D. and Frank, L. A.: Diagnosis of auroral dynamics using global auroral imaging with emphasis on large-scale evolution, in: Auroral Physics, edited by: Meng, C.-I., Rycroft, M. J., and Frank, L. A., pp. 273, Cambridge Univ. Press, New York, 1991.

Craven, J. D., Murphree, J. S., Frank, L. A., and Cogger, L. L.: Simultaneous optical observations of transpolar arcs in the two polar caps, Geophys. Res. Lett., 18, 2297-2300, 1991.

Crooker, N. U.: Dayside merging and cusp geometry, J. Geophys. Res., 84, 951-959, 1979.

Cumnock, J. A., Heelis, R. A., Hairston, M. R., and Newell, P. T.: High-latitude ionospheric convection pattern during steady northward interplanetary magnetic field, J. Geophys. Res., 100, 14537-14555, 1995.

Cumnock, J. A., Sharber, J. R., Heelis, R. A., Hairston, M. R., and Craven, J. D.: Evolution of the global aurora during positive IMF $B_{z}$ and varying IMF $B_{y}$ conditions, J. Geophys. Res., 102, 17486-17497, 1997.

Cumnock, J. A., Spann, J. F., Germany, G. A., Blomberg, L. G., Coley, W. R., Clauer, C. R., and Brittnacher, M. J.: Polar UVI observations of auroral oval intensifications during a transpolar arc event on December 7, 1996, Rep. TRITA-ALP-2000-01, Royal Institute of Technology, Stockholm, 2000.

Cumnock, J. A., Sharber, J. R., Heelis, R. A., Blomberg, L. G., Germany, G. A., Spann, J. F., and Coley, W. R.: Interplanetary magnetic field control of theta aurora development, J. Geophys. Res., 107(A7), 1108, doi:10.1029/2001JA009126, 2002.

Cumnock, J. A. and Blomberg, L. G.: Transpolar arc evolution and associated potential patterns, Ann. Geophys., 22, 1213-1231, 2004, http://www.ann-geophys.net/22/1213/2004/.

Cumnock, J. A.: High-latitude aurora during steady northward interplanetary magnetic Field and Changing IMF $B_{y}$, J. Geophys. Res., 110, A02304, doi:10.1029/2004JA010867, 2005.

Cumnock, J. A., Blomberg, L. G., Alexeev, I. I., Belenkaya, E. S., Bobrovnikov, S. Yu., and Kalegaev, V. V.: Simultaneous polar aurorae and modelled convection patterns in both hemispheres, Adv. Space Res., 38, 1685-1693, doi:10.1016/j.asr.2005.04.105, 2006.

Frank, L. A., Craven, J. D., Burch, J. L., and Winningham, J. D.: Polar views of the Earth's aurora with Dynamics Explorer, Geophys. Res. Lett., 9, 1001-1004, 1982.

Frank, L. A., Craven, J. D., Gurnett, D. A., et al.: The theta aurora, J. Geophys. Res., 91, 3177-3224, 1986.

Frank, L. A. and Craven, J. D.: Imaging results from Dynamics Explorer 1, Rev. Geophys., 26, 249-283, 1988.

Gusev, M. G. and Troshichev, O. A.: Hook-shaped arcs in dayside polar cap and their relationship to the IMF, Planet. Space Sci., 34, 489-496, 1986.

Gussenhoven, M. S.: Extremely high latitude auroras, J. Geophys. Res., 87, 2401-2412, 1982.

Heppner, J. P. and Maynard, N. C.: Empirical high-latitude electric 
field models, J. Geophys. Res., 92, 4467-4489, 1987.

Hones, E. W. J., Craven, J. D., Frank, L. A., Evans, D. S., and Newell, P. T.: The horse-collar aurora: A frequent pattern of the aurora in quiet times, Geophys. Res. Lett., 16, 37-40, 1989.

Huang, C. Y., Frank, L. A., Peterson, W. K., Williams, D. J., Lennartson, W., Michell, D. G., Elphic, R. C., and Russell, C. T.: Filamentary structures in the magnetotail lobes, J. Geophys. Res., 92, 2349-2364, 1987.

Huang, C. Y., Craven, J. D., and Frank, L. A.: Simultaneous observations of a theta aurora and associated magnetotail plasmas, J. Geophys. Res., 94, 10137-10143, 1989.

Iijima, T., Potemra, T. A., Zanetti, L. J., and Bythrow, P. F.: Large-scale Birkeland currents in the dayside polar region during strongly northward IMF: A new Birkeland current system, J. Geophys. Res., 89, 7441-7452, 1984.

Ismail, S. and Meng, C.-I.: A classification of polar cap auroral arcs, Planet. Space Sci., 30, 319-330, 1982.

Kullen, A.: The connection between transpolar arcs and magnetotail rotation, Geophys. Res. Lett., 27, 73-76, 2000.

Kullen, A., Brittnacher, M., Cumnock, J. A., and Blomberg, L. G.: Solar wind dependence of the occurrence and motion of polar auroral arcs: A statistical study, J. Geophys. Res., 107(A11), 1362, doi:10.1029/2002JA009245, 2002.

Kullen, A. and Janhunen, P.: Relation of polar auroral arcs to magnetotail twisting and IMF rotation: a systematic MHD simulation study, Ann. Geophys., 22, 951-970, 2004, http://www.ann-geophys.net/22/951/2004/.

Kullen, A., Cumnock, J. A., and Karlsson, T.: Seasonal Dependence and Solar Wind Control of Transpolar Arc Luminosity, J. Geophys. Res., 113, A08316, doi:10.1029/2008JA013086, 2008.

Lassen, K. and Danielsen, C.: Quiet time pattern of auroral arcs for different directions of the interplanetary magnetic field in the yz-plane, J. Geophys. Res., 83, 5277-5284, 1978.

Liou, K., Ruohoniemi, J. M., Newell, P. T., Greenwald, R., Meng, C.-I., and Hairston, M. R.: Observations of ionospheric plasma flows within theta auroras, J. Geophys. Res., 110, A03303, doi:10.1029/2004JA010735, 2005.

Marklund, G. T., Blomberg, L. G., Murphree, J. S., Elphinstone, R. D., Zanetti, L. J., Erlandson, R. E., Sandahl, I., de la Beaujardière, O., Opgenoorth, H., and Rich, F. J.: On the electrodynamical state of the auroral ionosphere during northward IMF: A transpolar arc case study, J. Geophys. Res., 96, 9567-9578, 1991.
Marklund, G. T. and Blomberg, L. G.: On the influence of localized electric fields and field-aligned currents associated with polar cap arcs on the global potential distribution, J. Geophys. Res., 96, 13977-13983, 1991.

Meng, C.-I.: Polar cap arcs and the plasma sheet, Geophys. Res. Lett., 8, 273-276, 1981.

Murphree, J. S. and Cogger, L. L.: Observed connections between apparent polar cap features and the instantaneous diffuse auroral oval, Planet. Space Sci., 29, 1143-1149, 1981.

Murphree, J. S., Anger, C. D., and Cogger, L. L.: The instantaneous relationship between polar cap and oval auroras at times of northward interplanetary magnetic field, Can. J. Phys., 60, 349-356, 1982.

Nielsen, E., Craven, J. D., Frank, L. A., and Heelis, R. A.: Ionospheric flows associated with a transpolar arc, J. Geophys. Res., 95, 21169-21178, 1990.

Obara, T., Mukai, T., Hayakawa, H., Nishida, A., Tsuruda, K., Machida, S., and Fukunishi, H.: Signature of electric field associated with localized electron precipitation in the polar cap region - Akebono (EXOS-D) results, J. Geomag. Geoelectr., 48, 327-335, 1996.

Obara, T., Mukai, T., Hayakawa, H., Tsuruda, K., Marsuoka, A., and Nishida, A.: Akebono (EXOS-D) observations of smallscale electromagnetic signatures relating to polar cap precipitation, J. Geophys. Res., 98, 11153-11159, 1993.

Peterson, W. K. and Shelley, E. G.: Origin of the plasma in a crosspolar cap auroral feature (theta aurora), J. Geophys. Res., 89, 6729-6736, 1984.

Sugiura, M.: A fundamental magnetosphere-ionosphere coupling mode involving field-aligned currents as deduced from DE-2 observations, Geophys. Res. Lett., 11, 877-880, 1984.

Sundberg, K. Å. T., Cumnock, J. A., and Blomberg, L. G.: The Reverse Convection Potential: A Statistical Study of the General Properties of Lobe Reconnection and Saturation Effects During Northward IMF, J. Geophys. Res., 114, A06205, doi:10.1029/2008JA013838, 2009.

Valladares, C. E., Carlson, H. C., and Fukui, K.: Interplanetary magnetic field dependency of stable Sun-aligned polar cap arcs, J. Geophys. Res., 99, 6247-6272, 1994. 